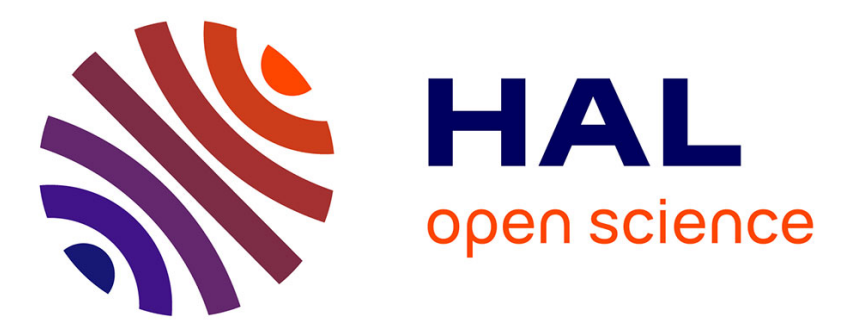

\title{
Adaptive single-carrier frequency-domain equalization for 100G coherent optical communications
}

Omid Zia-Chahabi, Raphaël Le Bidan, Michel Morvan, Christophe Laot

\section{To cite this version:}

Omid Zia-Chahabi, Raphaël Le Bidan, Michel Morvan, Christophe Laot. Adaptive single-carrier frequency-domain equalization for 100G coherent optical communications. SPPCom: Signal Processing in Photonics Communications, Jun 2011, Toronto, Canada. hal-00673283

\section{HAL Id: hal-00673283 https://hal.science/hal-00673283}

Submitted on 10 Jun 2021

HAL is a multi-disciplinary open access archive for the deposit and dissemination of scientific research documents, whether they are published or not. The documents may come from teaching and research institutions in France or abroad, or from public or private research centers.
L'archive ouverte pluridisciplinaire HAL, est destinée au dépôt et à la diffusion de documents scientifiques de niveau recherche, publiés ou non, émanant des établissements d'enseignement et de recherche français ou étrangers, des laboratoires publics ou privés. 


\title{
Adaptive Single-Carrier Frequency-Domain Equalization for 100G Coherent Optical Communications
}

\author{
Omid Zia-Chahabi, Raphaël Le Bidan, Michel Morvan, Christophe Laot \\ Institut Télécom/Télécom Bretagne, UMR CNRS 3192 Lab-STICC \\ Université européenne de Bretagne, Brest, France \\ omid.ziachahabi@telecom-bretagne.eu
}

\begin{abstract}
We investigate the principle and performance of fractionally-spaced adaptive single-carrier frequency-domain equalization for 16-QAM 100G coherent optical communications. The proposed solution is shown to be robust against linear impairments.
\end{abstract}

(C) 2011 Optical Society of America

OCIS codes: (060.1660) Coherent communications; (060.4510) Optical communications

\section{Introduction}

The use of multilevel modulation formats combined with digital signal processing enables spectrally-efficient longhaul coherent optical transmission. Linear time-domain equalization (TDE) has received much attention as a means for compensating chromatic dispersion (CD) as well as Polarization Mode Dispersion (PMD). In particular, adaptive algorithms based on the Least Mean Squares (LMS) or the Constant Modulus (CM) criteria have been extensively studied. However, TDE often requires filters with a large number of taps as the equalizer length increases linearly with the amount of $\mathrm{CD}$ to compensate [1]. In order to keep a low-complexity receiver, a frequency-domain implementation of the fixed CD compensating filter has been proposed [2].

Another frequency-domain approach is Single-Carrier Frequency-Domain Equalization (SC-FDE), which allows to jointly cope with CD and PMD at reduced complexity. SC-FDE for coherent optical communications has been studied in $[3,4]$. In [3,4], a symbol-spaced FDE is used. Known pilot symbols are periodically transmitted in order to estimate the channel and compute the FDE coefficients.

In this paper we propose an adaptive implementation of a fractionally-spaced SC-FDE. Fractionally-spaced equalizers (FSE) are more robust to a sampling phase error than symbol-spaced equalizers. After an initial training period, our algorithm tracks the channel variations in a decision-directed manner. Section 2 presents the structure and principle of the adaptive SC-FDE. Section 3 discusses performance of the system.

\section{The adaptive SC-FDE system}

SC-FDE is a frame-based single-carrier transmission technique that relies on a particular frame format in order to allow for efficient block equalization in the frequency domain at the receiver [5]. Specifically, data is segmented into blocks of $N$ symbols. As for OFDM, a cyclic prefix (CP) is added to the beginning of each block by reproducing the last $N_{c p}$ symbols of the block before transmission. The aim of the $\mathrm{CP}$ is twofold: removing interblock interference and turning the channel linear convolution into a circular one.

The single-input single-output (SISO) equalizer architecture is shown on Fig. 1b. For a $T / 2$-spaced equalizer, the received signal is sampled at twice the symbol rate. After $\mathrm{CP}$ removal and serial-to-parallel conversion, the samples are processed blockwise. A $2 N$-point FFT converts the received block into the frequency domain. The $2 N$ frequencydomain samples $Y_{l}$ are then weighted by the $2 N$ FDE coefficients $W_{l}$. In principle, a $2 N$-point IFFT should then be applied to return to the time domain, and the equalized signal should be downsampled at the symbol rate before entering the decision circuitry. It can be shown that downsampling can be advantageously realized directly in the frequency domain by adding the frequency components $l$ and $l+N$ for $0 \leq l \leq N-1$. By doing so, the IFFT length is reduced to $N$-point only. Then, the decided symbols $\hat{d}_{l}$ are subtracted to the equalized signal $z_{l}$ to form the error signal $e_{l}=z_{l}-\hat{d}_{l}$ whose discrete Fourier transform $E_{l}$ will be used to update the FDE coefficients.

For Polarization Division Multiplexed (PDM) transmission, four SISO FDEs are required to jointly cope with CD and polarization dependent effects, as illustrated in Fig. 1a. 

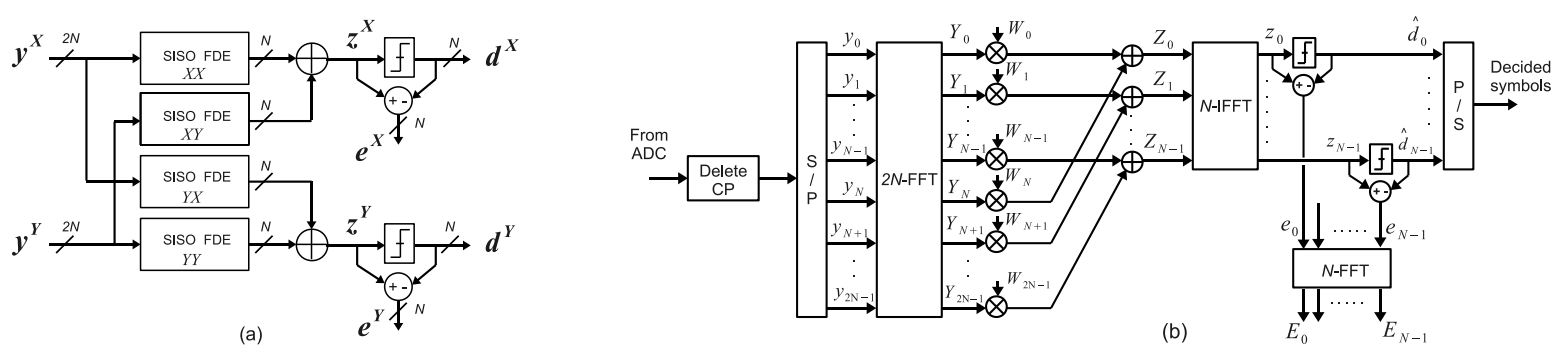

Fig. 1. The SC-FDE architecture: (a) The joint CD and PMD equalizer, (b) The SISO FDE

Adaptation of the FDE weights is based on a block LMS criterion in order to converge towards the equalizer that minimizes the mean square error over the block. As for LMS-based TDE, a preamble of known data blocks is required at the beginning of the transmission to train the FDE in a data-aided manner. After the initial training period, the FDE weights are continuously adjusted in a decision-directed manner.

\section{Simulation results}

In order to evaluate the performance of the proposed system, we simulate 112Gbit/s PDM-16QAM transmission (14Gbaud per polarization) over uncompensated ITU-T G.652 fiber with dispersion parameter $17 \mathrm{ps} / \mathrm{nm} / \mathrm{km}$. Transmit and receive electrical filters are square-root raised-cosine filters with roll-off factor 0.3 , and sampling at twice the symbol rate is performed after the receive filters. The structure of Fig. 1a is used for jointly equalizing CD and PMD. Perfect carrier synchronization is assumed, and no phase noise is considered.

Fig. 2a shows tolerance of our algorithm to CD for $N_{c p}=110$ symbols and $N=1024$ symbols ( $10.7 \%$ overhead), in a transmission with a fixed DGD of 90ps. The symbol rate has been increased to $15.5 \mathrm{Gbaud}$ to take the overhead into account. With these parameters, the equalizer is able to compensate up to $47000 \mathrm{ps} / \mathrm{nm}$ of CD, but is severely affected by interblock interference for higher values of CD (insufficient CP length). Finally, the dynamical behavior of the adaptive SC-FDE is evaluated using an endless polarization rotation, as suggested in [1]. Fig. 2b shows that the transmission suffers from an OSNR penalty of $1 \mathrm{~dB}$ for an angular frequency of $2 \times 10^{4} \mathrm{rad} / \mathrm{s}$.
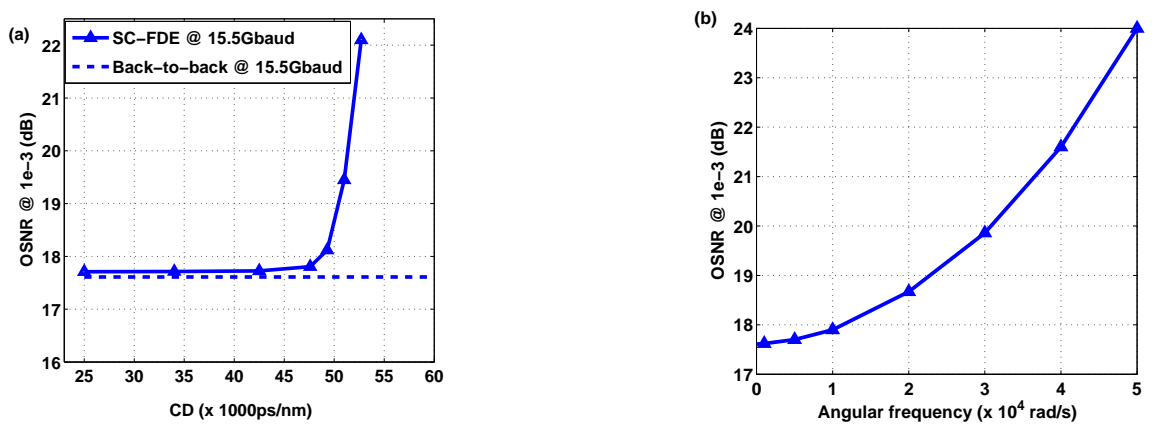

Fig. 2. (a) OSNR performance at BER $=10^{-3}$ vs. $\mathrm{CD}(\mathrm{DGD}=90 \mathrm{ps})$; (b) Dynamical behavior of the adaptive SC-FDE

\section{Conclusion}

We investigated a single-carrier transmission system using an adaptive frequency-domain equalizer for compensation of linear optical impairments.

\section{References}

1. S.J. Savory, Optics Express, vol. 16, no. 2, pp. 804-817, 2008

2. J.C. Geyer et al., OFC/NFOEC2010, paper OWV5, 2010

3. K. Ishihara et al., Electron. Lett., vol. 44, no. 14, pp. 870-871, 2008

4. R. Kudo et al., Electron. Lett., vol. 45, no. 2, pp. 124-125, 2009

5. H. Sari et al, IEEE Commun. Mag., vol. 33, no. 2, pp. 100-109, 1995 